\title{
The Effect Analysis of Perceived - expected Organizational Support Consistency on Employee Performance
}

\author{
Hongwei $\mathrm{Wu}^{1, *}$ and Yahui $\mathrm{Wang}^{2}$ \\ ${ }^{1}$ School of Economics, Huaibei Normal University, Huaibei 235000, China \\ ${ }^{2}$ School of Management, Shanghai University, Baoshan 200444, China \\ Corresponding author: whw121588@163.com
}

\begin{abstract}
The relationship between job performance and organizational support has attracted attention of the scholars in recent years, but empirical research on the mechanism of perceived expected organizational support consistency on employee performance is not much. Using Polynomial regression and the response surface analysis method, this paper discusses effect of the consistency between expected organizational support and perceived organizational support on employee job performance. The data analysis results show that when the expected organizational supports exactly the same consistency as perceived organizational support, the higher the perceived organizational support, the higher job performance is. When expected organizational support is higher than perceived, organizational support and job performance are in negative correlation. Then the paper makes several management suggestions from the working environment, executive support, tools support, emotional support and so on, in order to improve the effect of human resource management.
\end{abstract}

\section{Forward}

Globalization, informationization and servitization have made enterprises in an ever-changing environment. How to motivate employees' potential and make them work independently is the key to the development of enterprises, and it has an immeasurable promotion effect on improving enterprise competitiveness. Eisenberger (1986) [1] believed that organizational support is the employee's subjective perception of the organization's evaluation of the work results the and welfare, which can meet the emotional needs of employees to a certain extent, employees will increase the dedication and efforts after perceiving organizational recognition and awards. Borman (1993) [2] put forward that employee personality traits, responsibility, superior power distance, demographic characteristics such as age, gender, educational level, and length of service also have a certain effect on the perceived organizational support. Borman (1993) initially put forward job performance, and further subdivided into task performance and peripheral performance, in which task performance refers to the series of behavior under mandatory rules of the organization, peripheral performance refers to the employee's initiative services for the organization that do not even require income in return. By studying the performance of US Air Force employees, Motowidlo \& Van Scotter (1994) [3] found that task performance and peripheral performance act on the overall job performance independently of each other, and the roles of peripheral performance and task performance were separately analyzed from a practical point of view.

With regard to the relationship between the perceived organizational support and job performance and by using empirical data, Eisenberger(1986) [1] demonstrated that the perceived organizational support can reduce staff absence rate and promote job performance. Based on the above research and in the context of globalization, we have to think how modern enterprises, employee expectations and perceived organizational support have specific impact on the job performance? What is the specific internal mechanism? In this paper, response surface analysis was used to establish a polynomial regression equation, and the regression equation coefficient was used to reflect the basic characteristics of the three-dimensional graph. The non-linear response surface graph among the three variables of the equation were described using the statistical test results, the practical effect of the response surface's basic characteristics on the consistency level is expounded, and then the polynomial regression equation and its coefficient calculation process and the consistency empirical study are combined organically.

\section{Research Design}

\subsection{Operational definition and measurement of variables}


Indirect measures are mainly used by researchers on the consistency effect to assess the existing situation of independent employees and organizations without interference, and to evaluate the consistency by means of polynomial regression and other methods. This study focuses on the influencing mechanism of expected organizational support perceived organizational support consistency on the individual job performance, therefore, we mainly conducted indirect measurement by individual direction to assess the consistency degree of expected organizational support perceived organizational support.

\subsubsection{Perceived organizational support}

The data are measured with reference to the POS scale (Eisenberge, 1986) [1] and McMillin's instrumental organizational support concept, a new two-dimensional scale was formed through consolidation, the instrumental and emotional organizational support were selected for the real measurement. Instrumental organizational support mainly consists of three items, such as "the unit is always trying to provide me with high-quality working environment and supporting facilities", "the unit is always trying to provide me with job-related knowledge and staff support", etc; and seven items are specifically covered in emotional organizational support, such as "the organization values my contribution", "the organization respects my values and set goals", etc.

\subsubsection{Expected organizational support}

The data are measured with reference to the Perceived POS scale in item (1), instrumental and emotional organizational support were selected for the real measurement. Instrumental organizational support mainly consists of three items, such as "I expect the unit to provide me with high-quality working environment and supporting facilities", "I expect the unit to provide me with job-related knowledge and staff support", etc; and seven items are specifically covered in emotional organizational support, such as "I expect the organization to value my contribution", "I expect the organization to respect my values and set goals”, etc.

\subsubsection{Job performance.}

Task performance scale (3 items), such as "I can accurately complete my work objectives", "the quality of my work has been kept at a high level", etc; peripheral performance scale (4 items), such as "I am willing to stay in my department", "I am willing to do my best to work", etc.

Likert 7-point scale is the main measurement tool used in this paper. It consists of 7 degrees, and 1-7 means 7 different degrees from "totally disagree" to "fully agree".

\subsubsection{Control variable}

Some scholars have found that non-research variables such as age and gender have a deviation influence on employee job performance, and these four variables are also set as the control variables in job performance associated study. Therefore, this study will also control these variables to avoid errors.

\subsection{Questionnaire collection and sample characteristics}

The research object includes 24 enterprises and the geographical distribution of enterprises is in Shanghai, Sichuan, Guangdong. A total of 341 questionnaires were distributed and 238 were collected. The questionnaires with obvious similarities and some gaps were removed during data processing, finally obtaining a total of 152 credible samples.

From the sample descriptive statistics, men accounted for $52.8 \%$, women accounted for $47.2 \%$; degree of education: middle school or below (2.2\%), high school and college $(11.9 \%)$, junior college $(25.1 \%)$, college $(53.2 \%)$, graduate and above (7.6\%); employees sources include Shanghai (46.7\%), Sichuan (20.8\%) and Guangdong (32.5\%); traditional manufacturing industries $(5.3 \%)$, real estate $(6.4 \%)$, financial sector $(35.5 \%)$, IT sector $(8.2 \%)$, service sector $(10.8 \%)$, public institutions (9.6\%). Employee's years of service: 1 year (excluding) accounted for 3.7\%, 1 year (inclusive) or above and less than 5 years accounted for $9.9 \% ; 5$ years (inclusive) or above and less than 10 years accounted for 35.9\%; 10 years (inclusive) or above and less than 20 years accounted for $27.7 \%$; 20 years (inclusive) or above and less than 30 years accounted for $16.5 \%$; above 30 years accounted for $7.3 \%$.

\subsection{Validity evaluation of data structure}

The experimental data are less likely to produce statistical and systematic errors. The data processing is randomly reorganized by using the index Parceling, and then the reliability and validity of each concept are tested. SPSS19.5 and Lisrel8.0 were used in the test, and CR (composite reliability), Cronbach's Alpha coefficient and SMC (square multiple correlation) were mainly tested in reliability test. 
The experiment results show that the CR value of each variable is more than 0.5 , Cronbach's Alpha coefficients all exceed 0.7 (as shown in Table 1), and the SMC value of each item is 0.42 , greater than the critical value. All of the items have passed reliability test and the above results showed that the overall reliability of the questionnaires was high.

Table 1. Descriptive statistics and reliability and validity test of major variables

\begin{tabular}{|c|c|c|c|c|c|c|c|c|c|c|}
\hline & Mean & S.D. & $\begin{array}{c}\text { Cronbach } \\
\text { coefficient }\end{array}$ & CR & AVE & 1 & 2 & 3 & 4 & 5 \\
\hline $\begin{array}{c}\text { Perceived } \\
\text { emotional } \\
\text { POS }\end{array}$ & 4.11 & .89 & .862 & .791 & .546 & $(.768)$ & & & & \\
\hline $\begin{array}{c}\text { Perceived } \\
\text { instrumental } \\
\text { POS }\end{array}$ & 3.60 & .76 & .783 & .823 & .507 & $.329^{* *}$ & $(.719)$ & & & \\
\hline $\begin{array}{c}\text { Perceived } \\
\text { emotional } \\
\text { POS }\end{array}$ & 3.24 & .92 & .825 & .817 & .512 & $.341^{* *}$ & $.398^{* *}$ & $(.717)$ & & \\
\hline $\begin{array}{c}\text { Perceived } \\
\text { instrumental } \\
\text { POS }\end{array}$ & 3.34 & .96 & .893 & .743 & .534 & $.262^{* *}$ & $.473^{* *}$ & $.398^{* *}$ & $(.743)$ & \\
\hline $\begin{array}{c}\text { Job } \\
\text { performance }\end{array}$ & 3.63 & .97 & .867 & .757 & .565 & $-.206^{*}$ & $-.314^{* *}$ & $.244^{* *}$ & $-.314^{* *}$ & $(.741)$ \\
\hline
\end{tabular}

The validity of the questionnaires was checked by convergent and discriminate, respectively. Convergent uses the CFA tool to test whether the different observed variables can be used to evaluate the same construct (latent variable). Experiments show that the AVE values of each variable are more than 0.5 (the critical criterion). The variables reflect the absolute fitness index of covariance matrix generated by model against the overall model, the relative fitness index meets the specified requirements, which proves that the convergent of the data meets the specified level.

Discriminate tests whether there is significant difference between variables by comparing the AVE square root value of compare variable and the absolute value of the correlation coefficient between relevant variables. We calculated the AVE square root value of each variable and put it into the descriptive statistics and the diagonal line of correlation coefficient matrix table for a comparison, the results are shown in Table 1 (see Table 1). The AVE square root values of all variables are greater than the absolute value of the row-related and column-related coefficients, indicating that there is no discriminate problem of the data.

\subsection{Response surface analysis}

\subsubsection{Theoretical hypothesis and response surface features}

The polynomial regression and response surface analysis are used in this study. The polynomial regression method is used to construct the model, and the perceived organizational support and the expected organizational support are centralized by the center of the scale (value of 4). The polynomial regression method extends the constancy effect model of expected organizational support-perceived organizational support from the traditional two-dimensional space (plane) to three-dimensional space (three-dimensional). Job performance is taken as the dependent variable, expected organizational support and perceived organizational support are taken as independent variables for equation regression, the model formula is as follows:

$$
Z=b_{0}+b_{1} x-b_{2} y-b_{3} x^{2}+b_{4} x y-b_{5} y^{2}+e
$$

Where $\mathrm{z}$ denotes job performance, $\mathrm{x}$ denotes employee's perceived organizational support, and $\mathrm{y}$ denotes employee's expected organizational support. The formula allows for more detailed consideration of the mechanism of subtle relative differences between the two independent variables ( $\mathrm{x}$ and $\mathrm{y}$ ) on the primary dependent variable $\mathrm{z}$. It is easy to know by the structure of the equation that there are three high-order regression terms (including three terms of the third order or higher) in the polynomial equation, which are the second squared term of perceived organizational support, the interaction term of expected organizational support and perceived organizational support, and the quadratic term of expected organizational support.

It is assumed that the level of job performance increases with the consistency degree increase in expected organizational support and perceived organizational support, and that the consistency or complete matching of expected organizational support and perceived organizational support at the highest numerical value marks the job performance to a maximum for the employee. The basic assumption is mainly expressed in the three-dimensional graph as follows: (1) If the consistency of the maximal values of the expected organizational support and perceived organizational support makes the job performance to the maximum, the ridge of the response surface image is projected on the XY plane as a $\mathrm{Y}=\mathrm{X}$ straight line. In other words, the first principal axis of the response surface coincides with $\mathrm{Y}=\mathrm{X}\left(\mathrm{p}_{10}=\right.$ 
$0, \mathrm{p}_{11}=1$ ); (2) If the consistency effect between expected organizational support and perceived organizational support promotes the improvement of job performance, the response surface graph should be concave; (3) If the positive impact of the two dependent variables (perceived organizational support and expected organizational support) on the major dependent variable (job performance) is statistically significant, then the slope of the response surface image along the second principal axis should be 0 , but the curvature is not significantly 0 (Edwards, 2007) [4].

Based on the above consistency theory and the geometric characteristics of corresponding response surface image, it is proved that the verification of the consistency effect of the two independent variables by using polynomial regression equation and response surface analysis shall start from the following three aspects. First, verify that the response surface is centered on the original coordinate axes (X and $\mathrm{Y}$ ), and verify that the inflection point (extreme value) of the response surface is at the origin and whether the two principal axes coincide with $\mathrm{Y}=\mathrm{X}$ and $\mathrm{Y}=-\mathrm{X}$. By checking that the slope of the first principal axis and the second principal axis is not significantly $1(-1)$, it is possible to judge that the response surface rotates significantly along the principal axis, by verifying that the values of $-\mathrm{p}_{10} /\left(1+\mathrm{p}_{11}\right)$ and $-\mathrm{p}_{20} /(1$ $+\mathrm{p}_{21}$ ) are significantly not 0 , it is possible to judge that the response surface shifts along $\mathrm{Y}=\mathrm{X}$ or $\mathrm{Y}=-\mathrm{X}$. Second, the curvature and slope of the response surface along the two principal axes are calculated. If the curvature is not significantly 0 , the groove of the response surface (if curvature $<0$, the transversal is concave) or the ridge (if curvature $>0$, the transversal is convex) is not smooth; if the slope is not significantly 0 , it indicates that there is a slope at the intersection between the response surface along the transversal of the two principal axes and $\mathrm{Y}$-axis on the XY plane (or the intersection between response surface and the $\mathrm{Y}$-axis); finally, if the two principal axes of the response surface do not coincide $\mathrm{Y}=\mathrm{X}$ or $\mathrm{Y}=-\mathrm{X}$, it is also necessary to further calculate the curvature and slope of the response surface along the $\mathrm{Y}=\mathrm{X}$ and $\mathrm{Y}=-\mathrm{X}$ to analyze the three-dimensional shape of the response surface. If the curvature or slope of the response surface image along the $\mathrm{Y}=\mathrm{X}$ plane is not significantly 0 , it means that the independent variables have different effects on the dependent variables at different levels; the slope and curvature of response surface along $\mathrm{Y}$ $=-\mathrm{X}$ are visual indicators of the effect intensity of different consistency degree on the dependent variables.

\subsubsection{Test results and analysis}

In this paper, the SPSS 19.5 software is used to analyze and test the coefficients of the polynomial regression equation, and then the three-dimensional graphs of the response surface are drawn using the professional graphics software Origin 8.5. Figure 1 and Table 2 show the three-dimensional graphs of response surface, estimated values of the key indexes and data significance test results.

Table 2. Response surface data analysis $(\mathrm{N}=141)$

\begin{tabular}{|c|c|c|}
\hline \multirow{2}{*}{ Estimated parameters } & \multicolumn{2}{|c|}{ Model analysis results } \\
\cline { 2 - 3 } & $\begin{array}{c}\text { Estimate } \\
\text { d value }\end{array}$ & $\begin{array}{c}\text { Standard } \\
\text { deviation }\end{array}$ \\
\hline $\mathrm{X}_{0}$ & -2.66 & 4.034 \\
\hline $\mathrm{Y}_{0}$ & 0.04 & 0.065 \\
\hline $\mathrm{P}_{10}$ & 3.29 & 0.018 \\
\hline $\mathrm{P}_{11}$ & 1.21 & 0.027 \\
\hline $\begin{array}{c}\text { Slope (the first principal } \\
\text { axis) }\end{array}$ & 1.07 & 0.051 \\
\hline $\begin{array}{c}\text { Curvature (the first } \\
\text { principal axis) }\end{array}$ & $0.20 * *$ & 0.049 \\
\hline $\mathrm{P}_{20}$ & -2.15 & 1.541 \\
\hline $\mathrm{P}_{21}$ & -0.82 & 0.023 \\
\hline $\begin{array}{c}\text { Slope (the second principal } \\
\text { axis) }\end{array}$ & 0.35 & 0.051 \\
\hline $\begin{array}{c}\text { Curvature (the second } \\
\text { principal axis) }\end{array}$ & 0.07 & 0.075 \\
\hline Slope (Y=X) & $0.20^{*}$ & 0.012 \\
\hline Curvature (Y=X) & 0.08 & 0.028 \\
\hline Slope (Y=-X) & $0.40^{*}$ & 0.003 \\
\hline Curvature (Y=-X) & $0.16^{*}$ & 0.047 \\
\hline Note: $* \mathrm{p}<0.05 ; * * \mathrm{p}<0.01 ; * * * \mathrm{p}<0.001$, two-tailed test \\
\hline
\end{tabular}

According to the analysis of the response surface image and the results of the polynomial calculation, the following conclusions are drawn: First, the consistency between expected organizational support and perceived organizational support and employee job performance (Figure 1). The visualization of the image shows that the response surface is concave, and the inflection point coordinates $(-2.66,0.04)$ are calculated by the polynomial equation, and the value of $\mathrm{p} 10 /\left(1+\mathrm{p}_{11}\right)$ is 1.49 , the value of $-\mathrm{p}_{20} /\left(1+\mathrm{p}_{21}\right)$ is 11.94 , both are significantly not 0 , we can determine that there is no obvious translation of the response surface image along $\mathrm{Y}=\mathrm{X}$ and $\mathrm{Y}=-\mathrm{X}$. The transversal curve of the response surface along the first principal axis is a concave curve (curvature $=0.20$, n.s.), and the slope is greater than zero at the 
origin of the projection (slope $=0.35$, probably because the estimated standard error is not significant), indicating that the expected organizational support and perceived organizational support completely deviate from the impact on the job performance, appearing an inverted " $U$ " shape. That is to say, with the increase of the expected organizational support, job performance shows a trend of increasing first and then decreasing, along the second principal axis is a straight line with almost positive slope (slope $=0.35, \mathrm{p}<0.01$; curvature $=0.07$, n.s.), indicating that when the expected organizational support deviates from perceived organizational support, with the increase of perceived organizational support, job performance also increases. The slope of the response surface along the $\mathrm{Y}=\mathrm{X}$ transversal is a straight slope (slope $=0.2, \mathrm{p}<0.01$; curvature $=0.08$, n.s.), indicating that the higher the level of the consistency between the expected organizational support and perceived organizational support, the higher the level of job performance. While the transversal along $\mathrm{Y}=-\mathrm{X}$ is concave (curvature $=0.16, \mathrm{p}<0.01$ ), and the slope at the origin of the projection is $0.4(\mathrm{p}$ $<0.05$ ), indicating that when the expected organizational support and perceived organizational support is consistent, the individual's job performance level is higher than when the two are inconsistent. At the same time, when the expected organizational support deviates from perceived organizational support, with the increase of deviation degree, job performance level is declining faster and faster.

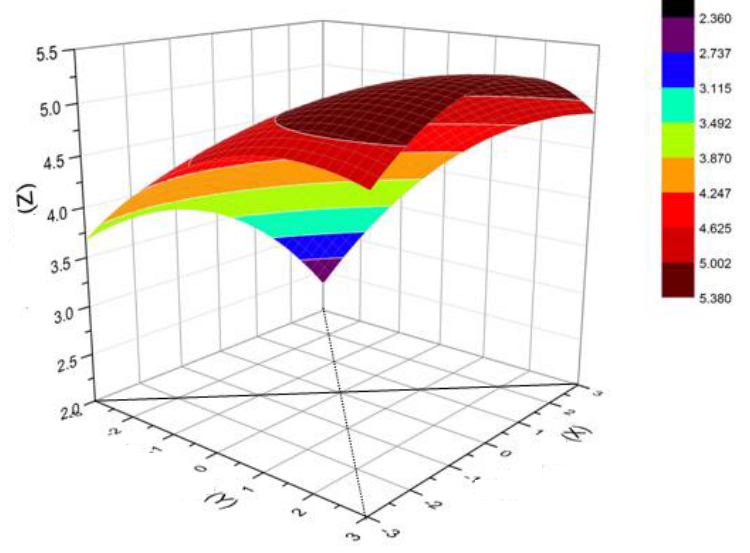

Fig. 1. Perceived - expected organizational support and employee job performance.

Note: $(Z)$ : Job performance; $(Y)$ : Perceived organizational support; $(X)$ : Expected organizational support

\section{Research Implications}

\subsection{Theoretical contribution of the research results}

Polynomial regression equation and response surface analysis can be used to obtain more information that can not be obtained by conventional methods, which can be expressed in the following three aspects: First, whether there is smooth and complete consistency between the two variables is verified exactly. The experiments show that binomial regression equation and response surface analysis method can objectively show the significant difference in the consistency effect of the independent variables at different levels (image display). Second, the main effect of single independent variable, the influence of consistency effect between two variables and the main effect of single independent variables on the consistency effect of two variables are investigated. Third, under the condition of incomplete consistency, the dependent variable values and changes with the independent variables are proved.

Edwards \& Cable (2009) [5], Edwards \& Parry(1993) [6] showed that there is very little perfect consistency effect. Under the premise of not completely matching, polynomial regression equation and response surface analysis have a great practical value to potential information. For example, the results of response surface analysis in this paper show that in some cases the consistency of expected organizational support and perceived organizational support is higher than that of the job performance at a high level of inconsistency, because the consistency effect of the dependent variable is weaker than the perceived outcome of a single dependent variable (organizational support and expected organizational support). If we use the traditional single method to analyze, simply pursuing the consistency degree between the expected organizational support and perceived organizational support, regardless of the level of a single variable, it may cause wrong guidance of the practical situation. Along with the in-depth research on consistency from domestic management and other aspects, the combination method and architecture of polynomial regression and response surface analysis will bring new thoughts to related domestic research, and are of great significance both in theoretical construction and practical guidance. 
Organizational support shall be brought into day-to-day organizational affairs to improve business-to-staff attention and support in order to reduce staff pressure, improve job performance, bring value-added business and thereby enhancing competitiveness of the industry.

\subsubsection{Optimize working environment, improve management methods}

First, companies should start from improving the working environment of employees, such as adjusting the workplace light, cleaning regularly and keeping the air fresh so as to create a work space with a sense of belonging as "home", and striving to reduce the pressure or obstruction caused by environmental discomfort on the staff. Moreover, the quality of interpersonal relationship in working environment is also closely related to employee performance, employees with a good interpersonal environment will have higher job satisfaction and more organizational commitment, virtually increasing employee's ability to adapt to and adjust organizational pressure. The communication between the horizontal (the same level) and the vertical (different levels) levels needs to be strengthened, and the employees are more likely to play their own creativity in an open and harmonious atmosphere, thus effectively improving the individual job performance.

\subsubsection{Learn from foreign management experience, implement EAP program}

Increase the intensity of executive support. Senior leadership is the embodiment of business for the grassroots employees, their support for employees will directly affect the employee's perceived organizational support intensity, and will effectively promote organizational commitment. Employees should be provided with good upper and lower levels of support whenever and wherever they need to improve their perceived organizational support. Improve the relationship between employees and direct supervisors, the trust relationship between employees and direct supervisors is one of the main factors affecting organizational support. Through communication and information transparency, we can reduce the distrust between employees and supervisors, managers can even achieve "govern by non-interference", the key lies in the establishment of mutually supportive relationship. This relationship will help to positively encourage employees' positive attitude and initiatives. On the contrary, if the direct leadership ignores the daily work of employees, do not give necessary emotional support to employees, it will lead to employees' negative slack, even jobhopping.

Provide tools support initiatively. Tools support mainly refers to the professional and technical training support and good external environment, etc. Employees from an enterprise that provides staff with initiative support have the highest perceived organizational support. In the long-term engagement in a particular industry and job, due to technical constraints, employees will have a strong sense of dependence to their current occupation, while they will have a large perception gap between their living skills in other industries and the actual experience, and a certain gap between reality perception, even questioning on their own future career planning, self-worth or the overall quality and ability. So managers need to strive more instrumental support for employees. Individuality shall be considered in the widespread use of initiative tools, different employees have different needs for vocational and technical education and training. For example, an employee in long-term engagement in accounting can take extra specialized knowledge training such as management expertise. In addition, the staff's gender, education, length of service, marital status and other factors will also affect the tools support. In short, tools support can achieve the best results only after developing an organizational support plan for each employee.

Emphasize emotional support. Emotional support emphasizes concerns of employees' emotional appeal and strong support. The organization needs to pay great attention to employee's well-being perception and related welfare measures. From the daily work and management point of view, the organization should always listen to the voice from the grassroots level, only the first-line employees understand the organization's operating conditions best. In addition, the organization can conduct regular psychological education and counseling for staff, once the staff have doubts on their own career planning, or career development encounters "ceiling", the organization needs to actively alleviate the pressure through psychological counseling to make them adapt to changes in the external environment as soon as possible. Furthermore, the organization's assessment of employee performance should be timely and effective, public and transparent feedback shall be made to the staff, providing effective solutions to problems encountered at work, practically concerning and safeguarding the rights and interests of employees, and effectively improving employees' perceived organizational support.

\section{Acknowledgement}

We are grateful to the referees for their constructive comments. We also appreciate the support of The 2016 Key Program in the Youth Elite Support Plan in Universities of Anhui Province (gxyqZD2016103).

\section{References}

1. R. Eisenberger, R. Huntington, S. Hutchison, J. Appl. Psychol. 71, 500-507 (1986).

2. W. Borman,.Human Performance, 6, 12-21 (1993). 
3. S. Motowidlo, J. Scotter, J. Appl. Psychol. 4, 475-480 (1994).

4. J. Edwards, Perspectives on organizational fit , 4, 361-372 (2007).

5. J. Edwards., D. Cable, J. Appl. Psychol. 94, 654-677 (2009).

6. J. Edwards, M. Parry, Acad. Manage. J. 36, 1577-1613 (1993). 